\title{
An Assessment of Indoor Air Quality (IAQ) in Metal industries of Delhi
}

\author{
Malvika Khullar, Dr. Puja Gupta
}

Department of Resource Management and Design Application, University of Delhi

\begin{abstract}
With growing realization and concern for our health, the focus on Indoor Air Quality has increased. Exposure to indoor air pollution is responsible for nearly 2 million excess deaths in developing countries and for some $4 \%$ of the global burden of disease. Today it is critical that the industry be familiar with the environmental hazards that employees are subjected to in the workplace. Iron \& steel and other manufacturing industries, foundries and forges produce a lot of pollutants in the indoor environment. Exposures to mineral dusts, metal fumes, products of combustion, resin bonding systems, physical noise and heat and vibration hazards may seriously impact the health of workers in foundries.
\end{abstract}

The study aimed at assessing Indoor Air Quality in Metal industries of Delhi in Mayapuri industrial area. The study was carried out in 3 phases. In the first phase, the study collated awareness about Indoor Air Quality and related health effects amongst the owners and employees working in the enterprises. In the second phase, the study involved monitoring of the randomly selected enterprises in terms of $\mathrm{CO}_{2}, \mathrm{PM}_{2.5}, \mathrm{PM}_{10}$ and presence of dampness and molds in the enterprises. The third phase involved spreading awareness regarding Indoor Air Quality amongst the sample.

Highlights of the study are:

Majority of the owners were aware about the concept of Indoor Air Quality and its relationship with productivity and health of a person. They could also cite some of the health impacts caused due to poor Indoor Air Quality. In spite of their wisdom on Indoor Air Quality, there were no monitoring and maintenance provisions in their enterprises.

Also, none of the owners provided their employees personal protective equipment (PPE) and any information or training regarding Indoor Air Quality and its health hazards.

Majority of the employees were unaware of the concept of Indoor Air Quality. The employees could neither relate health with Indoor Air Quality nor showed any interest in improving the same.

It was seen that there was a moderately high level of $\mathrm{CO}_{2}$ concentrations in the enterprises, mainly due to insufficient ventilation in the enterprises.
$P M_{2.5}$ concentrations were found to be poor and were almost double than its acceptable limits. While it was seen that $P M_{10}$ concentrations were within their acceptable limits.

It was observed that in majority enterprises presence of molds and dampness was observed. It was observed on walls and ceilings. The areas near the walls and places with molds were surrounded by a bad odor.

This study has been helpful in providing clear direction towards the Indoor Air Quality in Metal industries operating in Mayapuri. It also highlights the awareness regarding Indoor Air Quality amongst the sample. The study concludes that there is a sense of knowledge regarding Indoor Air Quality amongst the owners/managers of the enterprises but a huge scope in monitoring and maintenance provisions. The need for spreading awareness about IAQ and its related health effects were highlighted which would improve Indoor Air Quality in industries. The study showcased a clear scope for awareness generation and training amongst the owners and employees of the enterprises regarding Indoor Air Quality. The study suggests surveying of health status in metal industries and similar research in other industries. The findings were also shared with competent authorities to sensitize them towards poor Indoor Air Quality in the metal industries.

Keywords-Awareness, Exposure, Indoor Air Quality, metal industries, Pollutants

\section{INTRODUCTION}

Buildings create shelter and conditions for working, learning, leisure and comfortable living. A built environment should be safe with no health hazards for its users either due to poor design and construction, or due to poor operation, maintenance and performance. Negligence and/or compromise of any of the actions required to achieve high criteria set for the conditions indoors can bring about serious problems resulting in the substantial costs and numerous undesirable consequences. The holistic approach for creating indoor environmental quality in buildings is hence required involving different disciplines and harmonization with policies and regulations. Numerous determinants of healthy, productive and comfortable indoor environments must be 
considered comprising among others outdoor air pollution and climate, as well as the expectations and behavior of buildings' users to name just few (Achieving IAQ supporting health and comfort in highly energy efficient buildings, 2013) .

Metal industries are the indispensable part of an economy; they form the backbone of industrial development of any country. Iron and steel industry is by nature a heavy industry. Besides, iron and steel industry, heavy engineering and machine tools industries are the main dealers of metals. These industries have witnessed a phenomenal growth and produces a whole range of capital goods and consumer durables. The capital goods required for textile industry, fertilizer plants, power projects, cements, steel and petro-chemical plants, mining, construction and agricultural machineries such as equipment for irrigation projects, diesel engines, pumps and tractors, transport vehicles, etc. are being produced indigenously (Metal Industry in India, 2015).

In Iron \& Steel and other manufacturing industries, foundries and forges produce a lot of pollutants in the environment - both indoor and ambient environment. Processes for molding, melting and castings etc. are accompanied by evolution of heat, noise, dust fines, flyash, oxides of Nitrogen, Sulphur and metals. Particulate matters are generated in large quantities when preparing mold core sands and molds melting metals, pouring metal, knocking out poured molds and loading and unloading raw materials. Here metals are given a specific shape by metal castings for various engineering purposes. Pollutants are also emitted in sintering, pelletizing, rolling mills, coke-oven plants, refractories etc. in steel making and by-products manufacturing (Health hazards of Foundries and Forges, 2009).

Many people are exposed to common air pollutants in their occupations e.g. smoke, dust, SPM, RSPM, carbon mono-oxide, sulphur dioxide, oxides of nitrogen $\left(\mathrm{N}_{\mathrm{ox}}\right)$, hydrocarbons, and heavy metals like $\mathrm{Pb}, \mathrm{Cd}, \mathrm{Cr}, \mathrm{As}, \mathrm{Ni}$ etc. Their prolonged exposure causes various health hazards. Heavy metals cause acute and chronic poisoning. Some disastrous episodes have focused attention upon air pollution as a health hazard (Health hazards of Foundries and Forges, 2009).

\subsection{Indoor Air Quality}

Indoor air quality (IAQ) refers to the quality of the air inside buildings as represented by concentrations of pollutants and thermal (temperature and relative humidity) conditions that affect the health and performance of occupants. The growing proliferation of chemical pollutants in consumer and commercial products, the tendency toward tighter building envelopes and reduced ventilation to save energy, and pressures to defer maintenance and other building services to reduce www.ijeab.com costs have fostered IAQ problems in most of the buildings. As a result, occupant's complaints of stale and stuffy air, and symptoms of illness or discomfort breed undesirable conflicts among occupants/owners/tenants/building managers. Therefore, it has become one of the most important issues of environment and health worldwide considering the principle of human rights to health that everyone has the right to breathe healthy indoor air (Air Pollution, 2014) .

Some general health hazards are caused as a result of contact between the pollutants and the body. These hazards are as follows:

- Eye irritation

- Headache

- Noise and throat irritation

- Irritability of respiratory tract

- Gases like hydrogen sulphide, ammonia and mercaptans cause odor nuisance even at low concentrations

- High temperature can cause fatigue and dehydration

- Chronic pulmonary diseases like Bronchitis and asthma are aggravated by a high concentration of $\mathrm{SO}_{2}, \mathrm{NO}_{2}$, and particulate matter.

- Carbon monoxide combines with the hemoglobin in the blood and consequently increases stress on those suffering from cardiovascular and pulmonary diseases

- Dust particles cause respiratory disease (Health hazards of Foundries and Forges, 2009).

Indoor Air Quality (IAQ) refers to the air quality within and around buildings and structures, especially as it relates to the health and comfort of building occupants. Understanding and controlling common pollutants indoors can help reduce risks of indoor health concerns. Health effects from indoor air pollutants may be experienced soon after exposure or, possibly, years later. Some health effects may show up shortly after a single exposure or repeated exposures to a pollutant. These include irritation of the eyes, nose, and throat, headaches, dizziness, and fatigue. Such immediate effects are usually short-term and treatable. Sometimes the treatment is simply eliminating the person's exposure to the source of the pollution, if it can be identified. Soon after exposure to some indoor air pollutants, symptoms of some diseases such as asthma may show up, be aggravated or worsened. The likelihood of immediate reactions to indoor air pollutants depends on several factors including age and preexisting medical conditions. In some cases, whether a person reacts to a pollutant depends on individual sensitivity, which varies tremendously from person to person. Some people can become sensitized to biological 
or chemical pollutants after repeated or high level exposures.

Certain immediate effects are similar to those from colds or other viral diseases, so it is often difficult to determine if the symptoms are a result of exposure to indoor air pollution. For this reason, it is important to pay attention to the time and place symptoms occur. If the symptoms fade or go away when a person is away from the area, for example, an effort should be made to identify indoor air sources that may be possible causes. Some effects may be made worse by an inadequate supply of outdoor air coming indoors or from the heating, cooling or humidity conditions prevalent indoors. Other health effects may show up either years after exposure has occurred or only after long or repeated periods of exposure. These effects, which include some respiratory diseases, heart disease and cancer, can be severely debilitating or fatal. It is prudent to try to improve the indoor air quality in your home even if symptoms are not noticeable.

While pollutants commonly found in indoor air can cause many harmful effects, there is considerable uncertainty about what concentrations or periods of exposure are necessary to produce specific health problems. People also react very differently to exposure to indoor air pollutants. Further research is needed to better understand which health effects occur after exposure to the average pollutant concentrations found in homes and which occurs from the higher concentrations that occur for short periods of time.

\subsection{Causes of Indoor Air pollution}

Indoor pollution sources that release gases or particles into the air are the primary cause of indoor air quality problems. Inadequate ventilation can increase indoor pollutant levels by not bringing in enough outdoor air to dilute emissions from indoor sources and by not carrying indoor air pollutants out of the area. High temperature and humidity levels can also increase concentrations of some pollutants (Indoor Air Quality, 2015).

Some general health hazards are caused as a result of contact between the pollutants and the body. These hazards are as follows:

- Eye irritation

- Headache

- Nose and throat irritation

- Irritability of respiratory tract

- Gases like hydrogen sulphide, ammonia and mercaptans cause odor nuisance even at low concentrations

- High temperature can cause fatigue and dehydration

- Chronic pulmonary diseases like Bronchitis and asthma, are aggravated by a high concentration of
$\mathrm{SO} 2, \mathrm{NO} 2$, particulate matter and photochemical smog

- Carbon monoxide combines with the hemoglobin in the blood and consequently increases stress on those suffering from cardiovascular and pulmonary diseases

- Dust particles cause respiratory disease. Diseases like silicosis, asbestosis etc. result from specific dust

- Carcinogenic agents like PAH's, Cr(VI), Cd etc. cause cancer

- Hydrogen fluoride causes diseases of bone (fluorosis) and mottling of teeth

- Certain heavy metals like lead, cadmium, mercury, chromium, nickel, manganese etc. enter into body by inhalation, skin absorption and through food chain. They cause acute and chronic poisoning.

\subsection{Pollutants in Indoor Environment}

Dust, SPM, noise and gaseous pollutants pose a potential threat to health of workers in industries and populations residing in the surrounding areas. Dust also absorb gases and in such a combination prove to be a more serious health hazards due to synergism. It has recently been demonstrated that SO2 absorbed on submicroscopic particles penetrate deep into the lungs and this is a greater danger to health. Silicosis and siderosis are common diseases in foundry-men and forge shops workers. Most of the cases of silicosis, however, have arisen in the manufacture of silica containing materials and in foundry workers. Pottery industry got such a bad reputation for silicosis. Grinders in the cutlery industry using sandstone wheels died in large numbers from silicosis. Pneumoconiosis and black lung diseases are caused due to coal dust. Asbestosis is common in asbestos workers in industries.

Direct IR radiation poses a risk to sight. Contact with hot metal or hot water may result in severe burns. Workers exposed to gamma rays and related ionizing radiations suffer from several hazards. Explosion and fire hazards occur during handling of liquid metal and the presence of flammable chemicals \& liquid fuel. Iron foundry slag may be highly reactive if calcium carbide is used to desulphurize the iron (Shrivastava, 2009) .

Total Suspended Particulate Matter

TSP is mostly a primary pollutant, but some of it is formed as secondary pollutant. It consists of soot, dust, tiny objects of liquid, and other material. An increase in the incidence of respiratory diseases and gastric cancer has been linked with the increase in particulate level. The natural sources include volcanoes, forest fires, and desert land. Some manmade sources are steel industry, power plants, and flour mills. Agricultural activities also 
contribute to TSP loading. Particulate gradually settle back to earth and can cause people to cough, get sore throats, or develop other more serious breathing problems. Particulate matter also causes discoloration of buildings and other structures

\section{A. Carbon Dioxide}

Carbon dioxide emissions have increased significantly during 19th century because of the use of coal, oil and natural gas. It finds uses as a refrigerant, in fire extinguishers and in beverage carbonation. Higher concentrations can affect respiratory function and cause excitation followed by depression of the central nervous system. Contact with liquefied $\mathrm{CO}_{2}$ can cause frostbite. Workers briefly exposed to very high concentrations have effects like damage to the retina, sensitivity to light (photophobia), abnormal eye movements, constriction of visual fields, and enlargement of blind spots (Kumar) .

\subsection{Significance}

In recent years, with growing realization, people have become more aware of potential health and comfort problems that may be associated with poor indoor air quality.

In Iron \& Steel and other manufacturing industries, foundries and forges produce a lots of pollutants in the environment - both working and ambient environment. In the processes involved in foundries and forges, metals are extracted and produced from ores by various metallurgical processes and processes for moulding, melting and castings etc. are accompanied by evolution of heat, noise, dust fines, fly-ash, oxides of Nitrogen, Sulphur and metals. Particulate matters are generated in large quantities when preparing mould core sands and moulds melting metals, pouring metal, knocking out poured moulds and loading and unloading raw materials. Here metals are given a specific shape by metal castings for various engineering purposes (Health hazards of Foundries and Forges, 2009).

Health plays an important role in increasing the productivity of an individual. Therefore, it becomes important to study such sectors. The study can be used by government and other officials to know the current Indoor Air Quality status in metal industries operated in the study locale. It will also be helpful for the competent authorities to know the current status of IAQ in their enterprises. The study would also provide the definite direction to future researchers in the related fields.

\subsection{Objectives}

To assess Indoor Air Quality (IAQ) of Metal Industries and study occupant awareness.

1. To study awareness amongst sample related to Indoor Air Quality (IAQ) and related health hazards
2. To assess Indoor Air Quality of the enterprises in terms of:

- Insufficient ventilation
concentrations)

$\left(\mathrm{CO}_{2}\right.$

- $\mathrm{PM}_{10}$ levels

- $\mathrm{PM}_{2.5}$ levels

- Observe the presence of dampness and molds in the factory premise

3. To design and implement an awareness generation campaign to capacitate the sample about Indoor Air Quality and its health hazards

\section{CONCLUSION}

Buildings create shelter and conditions for working, learning, leisure and comfortable living. The holistic approach for creating indoor environmental quality in buildings is hence required involving different disciplines and harmonization with policies and regulations. Numerous determinants of healthy, productive and comfortable indoor environments must be considered comprising among others outdoor air pollution and climate, as well as the expectations and behavior of buildings' users to name just few.In Iron \& Steel and other manufacturing industries, foundries and forges produce a lot of pollutants in the environment - both indoor and ambient environment. Processes for molding, melting and castings etc. are accompanied by evolution of heat, noise, dust fines, fly-ash, oxides of Nitrogen, Sulphur and metals. Particulate matters are generated in large quantities when preparing mold core sands and molds melting metals, pouring metal, knocking out poured molds and loading and unloading raw materials. Here metals are given a specific shape by metal castings for various engineering purposes. Pollutants are also emitted in sintering, pelletizing, rolling mills, coke-oven plants, refractories etc. in steel making and by-products manufacturing.

Indoor air quality (IAQ) refers to the quality of the air inside buildings as represented by concentrations of pollutants and thermal (temperature and relative humidity) conditions that affect the health and performance of occupants. The growing proliferation of chemical pollutants in consumer and commercial products, the tendency toward tighter building envelopes and reduced ventilation to save energy, and pressures to defer maintenance and other building services to reduce costs have fostered IAQ problems in most of the buildings. As a result, occupant's complaints of stale and stuffy air, and symptoms of illness or discomfort breed undesirable conflicts among occupants/ owners/ tenants/ building managers.

Indoor pollution sources that release gases or particles into the air are the primary cause of indoor air quality 
problems. Inadequate ventilation can increase indoor pollutant levels by not bringing in enough outdoor air to dilute emissions from indoor sources and by not carrying indoor air pollutants out of the area. High temperature and humidity levels can also increase concentrations of some pollutants.

In recent years, with growing realization, people have become more aware of potential health and comfort problems that may be associated with poor indoor air quality.

Health plays an important role in increasing the productivity of an individual. Therefore, it becomes important to study such sectors. The study can be used by government and other officials to know the current Indoor Air Quality status in metal industries operated in the study locale. It will also be helpful for the competent authorities to know the current status of IAQ in their enterprises. The study would also provide the definite direction to future researchers in the related fields.

The present research 'An assessment of Indoor Air Quality in Metal industries of Delhi' is an endeavor to assess Indoor Air Quality in metal industries. The study also focused on assessing the awareness of the employees and owners of the enterprises regarding the concept of Indoor Air Quality.

The study was conducted in Mayapuri Industrial area, Phase 1, New Delhi. The study was carried out in 3 phases. For conducting the present study, 10 enterprises were selected randomly. In the first phase, awareness of the employees and owners was assessed by the researcher regarding Indoor Air Quality and related health effects. In the first phase, owner/managers and employees of the selected enterprises served as the sample. Owners were selected as they are the decision makers in an enterprise and employees as they are the ones who work in the enterprises and are affected the most by the decisions made by the management of an enterprise. They are the affected partners and were of a great help in gaining insight into the knowledge amongst them regarding IAQ. One owner/manager and 5 employees from each unit, served as a sample for this phase, making the sample size of 60. Tool used in the first phase was an interview schedule to Check the awareness amongst the owners and employees.

In phase 2, monitoring of the enterprises was carried out in terms on $\mathrm{CO} 2$ concentrations, $\mathrm{PM}_{2.5}$ and $\mathrm{PM}_{10} 8$ hour monitoring was carried out with the help of IAQ tools. The sample size for this phase was 10 enterprises, The enterprises were selected randomly. Tool used in phase 2 for monitoring of the enterprises was IAQ monitor.

The data was collected by the researcher through personal visits to the enterprises with the help of proposed tools. Number of visits were done to gather the complete data and each interview took around 25-30 minutes. The www.ijeab.com responses obtained from the managers/owners were analyzed both qualitatively and quantitatively with the help of tables and graphs. The information gathered was studied and analyzed keeping in mind the objectives of the study.

General profile of the enterprises: These enterprises were established between the years 1980 and 1996. These enterprises either run in partnership or have one proprietorship form of ownership pattern. These enterprises majorly involve Metal molding, casting, manufacturing grills, cutlery and window panels. $94 \%$ of the employees working in these units were males, while only $6 \%$ of the employees were females. These $6 \%$ females were employed for administrative purposes only. Awareness of the Owners/managers: Majority of the owner/managers were aware about the term Indoor Air Quality and its concept. They were aware that it affected their as well as their employees' productivity and were aware that there was a relationship between Indoor Air Quality and Health of the occupants. All of them also felt that it was important for them to improve Indoor Air quality of their enterprises. On the contrary, no one knew the type of pollutants that were emitted out of their processes. Even after having a good share of knowledge, majority of them took no measures to reduce impact of emissions indoors. Also, none of them gave any training or provided any information to the employees to aware them regarding Indoor air quality and its health effects. Awareness of the employees: Majority of the employees did not know anything about the concept and told the researcher that they were listening it for the first time. They were unaware of Indoor Air Quality and its related health effects and that it could affect their productivity. These results also give the researcher a scope in educating the employees about importance of improving Indoor Air Quality of a building. But on the contrary, a majority of the employees were aware about molds and its related health risks. All the employees knew that controlling moisture in the building or the factory could help control the growth of molds.

Enterprise monitoring: Out of 10 randomly selected enterprises, 6 of them had relatively high concentrations of $\mathrm{CO}_{2}$ mainly due to inadequate ventilation. Almost all the enterprises recorded the $\mathrm{PM}_{2.5}$ concentrations as much as double the threshold values whereas $\mathrm{PM}_{10}$ concentrations were found out to be within the limits.

\section{REFERENCES}

[1] (2013). Achieving Iaq Supporting Health And Comfort In Highly Energy Efficient Buildings, 1-2.

[2] Air Pollution. (2014, June). Retrieved From Cpcb: Http://Www.Cpcb.Nic.In/Proto-Ind_Airpollution_June2014.Pdf

[3] Health Hazards Of Foundries And Forges. (2009). 
[4] Indoor Air Quality. (2015, October 15). Retrieved February 2016, From United States Environmental Protection Agency: Http://Www.Epa.Gov/IndoorAir-Quality-Iaq/Indoor-Air-Quality-Building-Type

[5] Kumar, D. A. (N.D.). Introduction To Air Polution. Retrieved From Http://Www.Eng.Utoledo.Edu/ Akumar/Iap1/Introd uction.Htm

[6] Metal Industry In India. (2015). Retrieved From Indiabizclub.

[7] Shrivastava, A. K. (2009). Health Hazards Of Foundries And Forges. Kolkata. 